IZA DP No. 7993

The Miracle Drugs: Hormone Replacement Therapy and Labor Market Behavior of Middle-Aged Women

N. Meltem Daysal

Chiara Orsini

February 2014

Forschungsinstitut zur Zukunft der Arbeit Institute for the Study of Labor 


\title{
The Miracle Drugs: \\ Hormone Replacement Therapy and Labor Market Behavior of Middle-Aged Women
}

\author{
N. Meltem Daysal \\ University of Southern Denmark \\ and IZA \\ Chiara Orsini \\ London School of Economics
}

\section{Discussion Paper No. 7993 \\ February 2014}

\author{
IZA \\ P.O. Box 7240 \\ 53072 Bonn \\ Germany \\ Phone: +49-228-3894-0 \\ Fax: +49-228-3894-180 \\ E-mail: iza@iza.org
}

\begin{abstract}
Any opinions expressed here are those of the author(s) and not those of IZA. Research published in this series may include views on policy, but the institute itself takes no institutional policy positions. The IZA research network is committed to the IZA Guiding Principles of Research Integrity.

The Institute for the Study of Labor (IZA) in Bonn is a local and virtual international research center and a place of communication between science, politics and business. IZA is an independent nonprofit organization supported by Deutsche Post Foundation. The center is associated with the University of Bonn and offers a stimulating research environment through its international network, workshops and conferences, data service, project support, research visits and doctoral program. IZA engages in (i) original and internationally competitive research in all fields of labor economics, (ii) development of policy concepts, and (iii) dissemination of research results and concepts to the interested public.
\end{abstract}

IZA Discussion Papers often represent preliminary work and are circulated to encourage discussion. Citation of such a paper should account for its provisional character. A revised version may be available directly from the author. 
IZA Discussion Paper No. 7993

February 2014

\section{ABSTRACT}

\section{The Miracle Drugs: Hormone Replacement Therapy and Labor Market Behavior of Middle-Aged Women}

In an aging society, determining which factors contribute to the employment of older individuals is increasingly important. We examine the impact of medical innovations on the employment of middle-aged women focusing on the specific case of Hormone Replacement Therapy (HRT), a common treatment for the alleviation of negative menopausal symptoms. HRT medications were among the most popular prescriptions in the United States until 2002 when the Women's Health Initiative Study - the largest randomized control trial on women ever undertaken - documented the health risks associated with their long term use. We exploit the release of these findings within a Fixed Effect Instrumental Variable framework to address the endogeneity in HRT use. Our results indicate substantial benefits of HRT use to the short-term employment of middle-aged women.

JEL Classification: $\quad 11, \mathrm{H} 8, \mathrm{~J} 2$

Keywords: employment, pharmaceutical treatments, Hormone Replacement Therapy

Corresponding author:

Chiara Orsini

LSE Health and Social Care

Department of Social Policy

London School of Economics and Political Science

Houghton Street

London WC2A 2AE

United Kingdom

E-mail: chrorsini@gmail.com 


\section{Introduction}

The increase in labor force participation, and consequently, the increase in employment of women is one of the most striking trends in the twentieth century. Although this trend is likely due to the complex interaction of many factors, ${ }^{1}$ available research in economics recognizes, among other causes, the important role of medical innovation in shaping labor market behavior of both men and women (Duggan and Garthwaite, 2012). There are, in particular, some medical innovations that disproportionately affected and, most likely, continue to affect, women's labor market behavior. The advent of the birth control pill, for example, by allowing women to successfully control their fertility and therefore delay marriage, allowed women to increase their human capital (Goldin and Katz, 2002) and enter the labor market (Goldin and Katz, 2002; Bailey, 2006). Also, the development of bacteriology, the introduction of sulfominydes and antibiotics, and the diffusion of blood banks dramatically decreased the death rate for women during child delivery; improved the standardization of obstetric practices; increased availability of pre-natal care and reduced the incidence of post-partum disabilities (Albanesi and Olivetti, 2009). These medical advances, by dramatically improving the health of women of fertile age who decide to have children, were crucial to the increase in labor force participation of women in childbearing years between 1920 and 1965 (Albanesi and Olivetti, 2009).

Despite the evidence on the impact of medical innovations on women's labor market behavior during reproductive years, there is very little research on the labor market effects of medical innovations aimed at women at the end of their reproductive years, commonly known as "menopause transition". ${ }^{2}$ In this paper, we examine the impact of Hormone Replacement Therapy (HRT), the most effective medical treatment in

\footnotetext{
${ }^{1}$ For a historical perspective, see Goldin (1990), Goldin (2006) and Acemoglu et al. (2004). Black and Brainerd (2004) and Black and Strahan (2001) focus on how globalization and deregulation trends may have reduced discrimination against women in various occupations. Greenwood et al. (2005) studies the role of household technologies in women's attachment to the labor force. For a discussion of how the shift toward a service and skill-intensive economy has increased the proportion of jobs suitable for women, see, for instance, Weinberg (2000) and Black and Juhn (2000).

${ }^{2}$ Menopause transition is a period in which fertility progressively declines and women's hormones levels have an erratic pattern (Gardener and Shoback, 2007). To our knowledge, only one study considers the effect of menopause transition on women's labor market behavior: Mvundura, (2007). We discuss this and other related research in Section 3.
} 
alleviating the negative symptoms of menopause transition, on short-term labor market outcomes of middleaged women using data from the Medical Expenditure Panel Survey. ${ }^{3}$ This is an important question for several reasons.

First, there is an extensive body of literature linking poor health to lower levels of labor market behavior (Currie and Madrian, 1999). Given that all women experience menopause and 80 percent of these women report experiencing (sometimes severe) negative health symptoms during the menopause transition, including main causes of mood disturbances such as vasomotor symptoms (hot flashes) and genital atrophy (Gardener and Shoback, 2007), understanding how medical treatments of these symptoms impact labor market outcomes is important.

Second, given the substantial rise in medical and pharmaceutical expenditures, policy-makers are increasingly interested in uncovering the returns to medical treatments. HRT, administered through prescription drugs, is the most common medical treatment of menopausal symptoms. For example, Premarin, one of the most commonly used HRT drugs, ranked second in the United States in 2001 (the first year in our sample) in terms of the number of purchased prescriptions and eighth in terms of total drug expenditures. ${ }^{4}$

Empirical identification of the effect of HRT use on employment is difficult, however, because of the endogeneity in HRT use. A woman's decision to use HRT may be related to her (unobserved) preferences for work. In addition, in the United States the primary means to obtain health insurance (which may lower the costs of HRT prescriptions) is through one's employer and as such we may be concerned about a potential reverse causality bias. In order to address the endogeneity in HRT use, we first take advantage of the panel nature of our data and implement individual fixed effects models. Our results using fixed effects models indicate that HRT use increases the short-term employment of women aged 40 to 55 (the group most likely to suffer from negative symptoms associated with the menopause transition, hence our "treatment" group), by 2.44 percent.

\footnotetext{
${ }^{3}$ The nature of the panel data used in this paper does not allow us to investigate long-term effects of HRT use.

${ }^{4}$ According to data from the Medical Expenditure Panel Survey, 53,789,424 Premarin prescriptions were purchased in 2001 with a total expenditure of $\$ 1,954,439,720$. (see http://www.meps.ahrq.gov/mepsweb/data_stats/summ tables/hc/drugs/2001/hcdrugest totpur2001.shtml and http://meps.ahrq.gov/mepsweb/data_stats/summ tables/hc/drugs/2001/hcdrugest_totexp2001.shtml).
} 
While the use of fixed effects methods alleviates concerns about a bias arising from individual timeinvariant factors, it does not eliminate the possibility of a bias from time-varying unobservable determinants of employment that are also correlated with HRT use. Hence, our second method exploits the release in 2002 of the findings of the Women's Health Initiative Study (WHIS) - the largest randomized controlled trial of women's health - which demonstrated that long-term HRT use increases the risk of heart attacks, stroke, blood clots and breast cancer among healthy post-menopausal women. As we detail in Section 2, the HRT component of the WHIS was scheduled to run until 2005 but the study was abruptly terminated in July 2002 in the interest of safety. The findings of the study made front pages in all major newspapers and were covered in broadcasts on national television. There was also a strong response to the findings from policy-makers. In particular, the Food and Drug Administration issued a mandate in January 2003 requiring all HRT drugs to include a boxed warning on the increased safety risks. In Figure 1, we show that there is a powerful association between the post-WHIS period and the HRT use among middle-aged women. Using data from the Medical Expenditure Panel survey for 1999-2004, we show a sharp decline in HRT prescription purchases after the WHIS among women aged 40 to 55. Figure 2 shows a decline in employment among women in this age group during the same period, suggesting a possible link between the two phenomena.

However, it is possible that the decline in female employment is caused by other shocks that impact the labor market of women and occur at the same time as the release of the WHIS findings. We therefore use women aged 58 to 70 who do not use HRT to control for employment trends of women aged 40 to 55 . The result is an instrumental variable strategy where the identifying instrument for HRT use is given by an interaction term: a post-WHIS dummy variable interacted with a dummy variable for those women aged 40 to 55. Our fixed effects instrumental variables indicate that HRT use increases short-term employment by 32.6 percentage points among women who were induced to not take HRT due to the WHIS findings, but who would have taken HRT otherwise. 
Our FE IV results represent a Local Average Treatment Effect (LATE) for the sample of compliers.

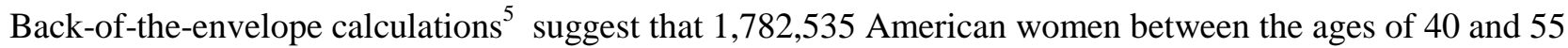
belonged to this group during 2001-2003, representing 5.3 percent of women in this age group. While compliers likely do not represent the average women undergoing the menopause transition, they are plausibly more representative of women experiencing menopausal symptoms that interfere with or prevent regular activities. In fact, evidence from the medical literature suggests that women who experience more severe symptoms are more likely to seek medical help to alleviate such symptoms. For example, using a sample of 454 women aged 45-55 who were premenopausal at baseline and were interviewed 5 times at yearly intervals, Avis et al. (1997) find that frequency and severity of menopausal symptoms were highly related to seeking medical consultation for menopause symptoms. This tendency is also found by Fentiman et al. (2006) in a sample of women aged 45 or older who identified themselves as non-users of HRT because "the symptoms associated with the menopause transition were not bad enough." Medical literature also suggests that menopausal symptoms can be severe enough to prevent usual activities. For example, an early retrospective study of a sample of 1000 women who had their last period five years or more before the study reports that 10.3 percent of respondents recalled to have or have had such severe disturbances related to menopause that they were compelled to bed rest or to absent themselves from work (Barrett et al., 1933).

We contribute to the small but growing literature in economics that examines the economic benefits of pharmaceutical treatments. As we detail in Section 3, this literature generally focuses on at-risk individuals (e.g., Thirumurthy et al., 2008; Berndt et al., 1998) and those with chronic conditions (e.g., Garthwaite, 2012). In contrast, we examine the labor market effects of HRT, a common pharmaceutical treatment used to alleviate negative menopausal symptoms. Consistent with the previous literature, we find substantial economic benefits of HRT use that should be taken into account when considering its cost-effectiveness.

Our results speak directly to the current policy debate on the link between pharmaceutical treatments and rising medical expenditures. The U.S. Department of Health and Human Services predicts pharmaceutical expenditures to double between 2008 and 2017 (Center for Medicaid and Medicare Services, 2007). We

\footnotetext{
${ }^{5}$ We use Census data for the calculation, see Section 6.
} 
contribute to this debate by providing a convincing research design to evaluate the non-health merits of HRT use - a highly relevant question given that menopause is a natural physical change experienced by all women (provided that they live long enough to reach middle age) and a sizeable share of these women go through negative health symptoms.

The paper proceeds as follows: section 2 provides background information on HRT and menopausal transition as well as the history of the WHIS; section 3 provides a review of the literature; section 4 describes the data; section 5 presents the empirical strategy; section 6 presents the results including a discussion on the role of health as the mechanism linking HRT use to labor market outcomes; and section 7 presents our conclusion.

\section{Background}

\subsection{Menopause and Hormone Replacement Therapy}

Menopause, which marks the end of a woman's fertile years, is a clearly defined event starting twelve months after a woman's last period. The median age at menopause is 51 (North American Menopause Society, 2006) and has remained remarkably stable over time (North American Menopause Society, 2006). Most women experience menopause from age 40 until age 55 with very few exceptions experiencing menopause at younger or older age ages (Jacobsen et al., 2003; Broekmans et al., 2007).

The menopause transition is a period that starts with increased variability in menstrual cyclicity and ends with the final menstrual period. During the menopause transition, female ovaries shrink and the hormones primarily produced by them (estrogen and progesterone) start to fluctuate, sometimes with very high or very low chaotic patterns (Gardener and Shoback, 2007). This dramatic variability may lead to an increase in symptomatology during the perimenopause years (Gardener and Shoback, 2007). The disorders associated with changes in estrogen levels include vasomotor symptoms and urogenital atrophy.

Vasomotor symptoms are commonly denoted as hot flashes if they occur during the day and are known as night sweats if they occur during the night. Symptoms associated with hot flashes include: a feeling 
of warmth spreading through the upper body and face; a flushed appearance with red, blotchy skin; rapid heartbeat; perspiration, and a chilled feeling when hot flashes subside. Nighttime hot flashes can wake the subject from sleep and, over time, cause chronic insomnia. These sleep disturbances eventually can lead to memory problems, anxiety and depression in some women (Gardener and Shoback, 2007). Vasomotor symptoms are experienced with greatest frequency during the stages in which the menstrual cycle becomes erratic (generally defined as two skipped cycles) and can occur for a period of up to five years after the last menstrual period.

The urogenital tract (Strurdee and Panay, 2010) is also sensitive to the decline in estrogen and it is estimated that about half of postmenopausal women experience symptoms related to urogenital atrophy. Although some symptoms, like vaginal dryness, start in the early postmenopausal years (Strurdee and Panay, 2010), vaginal atrophy becomes clinically apparent 4 to 5 years after menopause.

HRT is a treatment that involves taking small doses of female hormones that the natural aging process takes away. It is found to be the best medical remedy for hot flashes and urogenital atrophy (Gardener and Shoback, 2007). Once started, it takes only two weeks for HRT to successfully reduce negative symptoms experienced during the menopause transition (Watkins, 2007a). Partly due to their effectiveness, HRT prescriptions were very popular during the pre-WHIS period. The available statistics reflect this popularity with the number of oral estrogen prescriptions increasing from 14 million in 1980 to 20 million in 1986 to 31.7 million in 1992 (Kennedy, 1985; Hemminki et al, 1988; Wysowski et al., 1995). In that year, Premarin, the conjugated estrogen by Wyeth-Ayerst Laboratories, became the most frequently prescribed drug in the United States and remained in the top two most prescribed drugs for every year during the 1990s (Watkins, 2007a). Given the prevalence in HRT use, the findings of the WHIS documenting the safety risks of longterm HRT use were received with much interest by the medical professionals, the policy-makers, and the public. We turn to the WHIS and its findings in the next section. 


\subsection{The Women's Health Initiative Study}

The WHIS was launched in April 1991 with the aim of evaluating the effectiveness of several strategies for preventing major diseases and promoting good health among post-menopausal women. The study was composed of four clinical trials and one observational study. A federally funded program, the WHIS started recruiting women in 1998 and had 161,800 participant postmenopausal women aged 50 to 79. Among the four clinical trials, the one most closely watched was the HRT trial randomizing 16,608 women into a treatment group that received estrogen-progestin versus a control group that received a placebo. ${ }^{6}$ While the trial was supposed to run until March 2005, it was abruptly terminated in July 2002 in the interest of safety. The Writing Group for the Women's Health Initiative Investigators released the results of the trial to the medical community on July 9, 2002 with an article posted online at the Journal of the American Medical Association. According to the findings, women in the treatment group had an increased risk of breast cancer (26 percent higher than the control group), coronary heart disease (29 percent higher), stroke (41 percent higher) and blood clotting (213 percent higher). The treatment group also had a decreased risk of colorectal cancer (36 percent), endometrial cancer (17 percent) and hip fracture (34 percent). The above numbers in absolute terms implied eight more breast cancers; seven more coronary heart disease events; eight more strokes; eight more blood clotting, but six fewer colorectal cancers and five fewer hip fractures per ten thousand women each year (Watkins, 2007a).

The results were widely reported in the popular media, with a diverse degree of accuracy (Watkins, 2007a). The FDA took notice and in early January 2003 announced a formal name change for HRT drugs as "menopausal hormone therapy" and mandated that all estrogen and estrogen-progestin products include a boxed warning on their labels about the increased risk of heart attacks, strokes, blood clotting and breast cancer among postmenopausal women. The FDA currently recommends HRT use for relief of "moderate to severe vasomotor symptoms associated with menopause, treatment of vulvar and vaginal atrophy, and

\footnotetext{
${ }^{6}$ The other participants were sorted into an HRT trial randomizing estrogen-only drugs for women without a uterus, a trial testing whether calcium and vitamin D reduced fractures, and a trial involving dietary modification to test whether a low-fat diet prevents breast and colorectal cancer. Finally, the observational study involved 100,000 women who were not asked to take any medication or modify their lifestyle. The main goal of the observational study was to provide additional knowledge about risk factors for a range of conditions, such as cancer, fractures and cardiovascular diseases (The Women's Health Initiative Study Group, 1998).
} 
prevention of postmenopausal osteoporosis" and emphasizes that any HRT treatment should be done in the lowest dose and for the shortest necessary duration. While the main findings of the WHIS and the subsequent policy messages concerned long-term HRT use among postmenopausal women, Figure 1 indicates that there were substantial spillovers to middle-aged women's consumption of HRT products.

Overall, the discussion in this section suggests that the abrupt termination of the HRT trial, the highly publicized nature of the findings, and the strong response of policy makers to the news make the release of the WHIS findings an ideal quasi-experiment when examining the impact of HRT use on labor market outcomes.

\section{Related Literature}

Our paper is related to three strands of literature. First, we contribute to previous economic studies examining the labor market effects of pharmaceuticals. ${ }^{7}$ The majority of this literature focuses on at-risk individuals, such as those with HIV/AIDS (e.g., Thirumurthy et al., 2008) and the mentally ill (e.g., Berndt et al., 1998), and on individuals with chronic conditions such as arthritis (e.g., Garthwaite, 2012). A common finding is that pharmaceutical treatments are beneficial for the labor market outcomes of the impacted individuals. We add to this growing body of research by examining the impact of pharmaceuticals intended to alleviate negative symptoms of menopause - a natural physical change experienced by all women if they live long enough to reach middle age.

To our knowledge only one other paper has examined this question. Using data from the National Longitudinal Survey of Young Women for 1995-2003, Mvundura (2007) examines the impact of different phases of the menopause transition on labor market outcomes. ${ }^{8}$ While the primary focus of the paper is on the effect of different phases of menopause transition, it also checks whether the impact of these phases on labor market outcomes vary by HTR use status. Using panel data models, Mvundura (2007) finds that HRT use increases the labor force participation of those who had surgical menopause but does not find any evidence of

\footnotetext{
${ }^{7}$ For a review of this literature, see Duggan and Garthwaite (2012).

${ }^{8}$ The menopause transition stages include premenopause, perimenopause, surgical menopause and natural postmenopause. The labor market outcomes studied are labor force participation, weekly hours worked, full time employment and an indicator for self- employment.
} 
a differential impact for individuals at the perimenopause or natural postmenopause stage. There is also no evidence of a differential impact on number of hours worked or the likelihood of full-time and selfemployment. The major limitation of this study is the possibility of a remaining bias from unobserved timevarying determinants of employment that are also correlated with HRT use or from reverse causality (e.g., if women decide to work in order to have health insurance). In this paper, we explicitly address this issue using a novel source of exogeneous variation in HRT use within a fixed-effects instrumental variables framework.

Our paper is also related to the medical literature investigating the impact of HRT use on health since an extensive literature in economics documents that health has a direct effect on labor force participation (see Currie and Madrian, 1999). Conducting a meta-analysis of twenty one clinical trials, MacLennan et al. (2001) find that HRT treatments are highly effective in treating vasomotor symptoms with a 77 percent reduction in the frequency of weekly hot flashes, as well as their severity, when compared to a placebo. Similarly, using a sample of 875 postmenopausal women aged 45-64 randomly assigned to a placebo or four different regimes of estrogen and estrogen plus progestin treatment, Greendale et al. (1998) find marked improvements in selfreported vasomotor symptoms among the treated one year after the start of the trial. Finally, conducting a meta-analysis, Cardozo et al. (1998) find that HRT treatments are also effective in the treatment of urogenital atrophy. Given this evidence and the economics research linking health and labor market outcomes, it is logical to hypothesize that HRT may impact labor market outcomes through changes in individual health.

\section{Data}

We use two sources of data to conduct the empirical analysis. The first one is the Household Component of the Medical Expenditure Panel Survey (MEPS), a comprehensive, nationally representative survey of the U.S. civilian non-institutionalized population. Respondents in MEPS are surveyed about their medical care use, health related behavior, perceived health status, and expenditures over a period of two years through five interview rounds. Moreover, MEPS queries respondents on their labor market behavior, so that information on employment, hours of work and wages are available in each interview round. 
We focus on panels 6 and 7 of the Household Component spanning years 2001-2003 because these two panels contain information on the same individuals before and after the release of the WHIS findings. The "treatment" group consists of women aged 40 to 55 since the medical literature suggests that the negative symptoms of the menopause transition are most likely to manifest themselves during these ages. ${ }^{9}$ As discussed before, the treatment group experienced a substantial decline in HRT use after the release of the WHIS findings during which there was also a decline in employment. In order to control for secular trends in female employment, we use women aged 58 to 70 who do not use HRT as a "control" group. ${ }^{10}$

We link the annual Full Year Household Component consolidated data files with the prescription medicine component of MEPS. The latter includes information on respondents' prescription purchases in each round along with the three digit International Classification of Disease Codes 9 (ICD9) of the conditions for which each prescription medicine was purchased. The unit of analysis in the prescription data is the individual prescription for each respondent in the calendar year. We classify respondents as using HRT if at any time during the round they report having purchased HRT products at least once. In order to successfully link HRT prescriptions with the MEPS Household Component we need to identify the HRT prescription medicines available on the market during the period under study. We obtain this information from the Physician's Desk Reference Companion Guide (PDRCG), an annual publication that lists under the "Therapeutic Indications Index" all the medications along with the conditions for which they are indicated. HRT prescriptions (both brand names and generics) can be found under the label "Menopause, Vasomotor Symptoms of." Our final dataset, including information on labor market behavior and HRT use of each respondent, contains 21,731 observations. Table 1 provides summary statistics for selected variables.

\section{Empirical Strategy}

We are interested in examining the causal effect of HRT use on the labor market outcomes of middleaged women. The primary challenge stems from the endogeneity in HRT use. For example, women who are

\footnotetext{
${ }^{9} \mathrm{http} / /$ familydoctor.org/online/famdocen/home/women/reproductive/menopause/125.html.

${ }^{10} \mathrm{We}$ discuss the choice of the control group in more detail in Section 5.
} 
more attached to the labor market may prefer to use HRT. Similarly, we may be concerned about reverse causality whereby employment facilitates access to health insurance and thus to HRT treatment. Failing to account for this could lead to a spurious correlation between HRT use and labor market outcomes. In order to account for this potential endogeneity, we first identify the effects of HRT use on employment using panel data models.

They key equation of interest can be described as:

$$
y_{i t}=\gamma_{i}+H R T_{i t} \delta_{1}+X_{i t} \delta_{2}+\text { year }_{t} \delta_{3}+\eta_{i t}
$$

where the unit of observation is woman $i$ in interview round $t$ (which represents roughly a period of 5 months). ${ }^{11}$ The outcome variable, $y_{i t}$, is a dummy variable that equals 1 if woman $i$ is employed in round $t$ and 0 otherwise. The main independent variable, $H R T_{i t}$, is an indicator that takes on the value 1 if the respondent reports having purchased an HRT product at least once during round $t . X_{i t}$ is a set of exogenous covariates, including a cubic in age, and a panel-specific linear time trend. The panel-specific linear time trend controls for learning within each panel. In particular, respondents may change the way they answer questions over time because they get accustomed to taking surveys. year $r_{t}$ is a set of dummy variables equaling 1 in year $t$ and 0 otherwise. Finally, $\gamma_{\mathrm{i}}$ is a fixed effect that corrects for selection into HRT use based on unobserved individual characteristics that are time-invariant or that change slowly over time.

The key identifying assumption of this fixed effects (FE) model is that HRT use is uncorrelated with unobserved factors that vary over time and are, in turn, correlated with the outcome. More formally, if:

$$
E\left(\eta_{i t} \mid H R T_{i}, X_{i}, \gamma_{i}, \text { year }\right)=0, \quad \mathrm{t}=1,2, \ldots, \mathrm{T}
$$

\footnotetext{
${ }^{11}$ We model HRT use in period $t$ as affecting the outcome variable in period $t$ because the medical literature suggests that it takes only two weeks for HRT to effectively reduce negative symptoms experienced during the menopause transition (Watkins, 2007a).
} 
then $\delta_{1}$ represents the causal effect of HRT use on labor market outcomes. This assumption, while commonly made in panel data applications, is non-trivial as there are many time-varying factors that could affect both HRT use and labor market outcomes. For example, temporary fluctuations in individual productivity could induce individuals to take up HRT treatments (reverse causality).

To address this issue, we implement a fixed-effects instrumental variables (FE IV) strategy. In particular, we exploit the information on the harmful effects of long-term HRT provided by the WHIS as an exogenous source of variation in HRT use. As discussed in Section 2.2 the WHIS was abruptly terminated due to safety concerns, the findings were highly publicized and followed by strong policy responses. Motivated by this observation, we construct an instrumental variable for HRT use based on the timing of the release of the WHIS findings. Since there may be other factors that impact the labor market outcomes of middle-aged women and occur at the same time as the release of the WHIS findings, we incorporate in our analyses women aged 58 to 70 who do not use HRT as a control group. The identifying instrument for HRT use is given by an interaction term: a post-WHIS dummy variable interacted with a dummy variable for the treatment group. The following equations describe the first stage and the reduced form, respectively:

$$
\begin{aligned}
& H R T_{i t}=\theta_{1 i}+\text { Post }_{t} * \text { Women } 4055_{i t} \lambda_{1}+X_{1 t} \psi_{1}+\text { year }_{t} \rho_{1}+\xi_{1 i t} \\
& y_{i t}=\theta_{2 i}+\text { Post }_{t} * \text { Women } 4055_{i t} \lambda_{2}+X_{i t} \psi_{2}+\text { year }_{t} \rho_{2}+\xi_{2 i t}
\end{aligned}
$$

where Post $t_{t}$ is an indicator for the period after July 2002 and Women $4055_{i t}$ is an indicator for those women aged 40 to 55 . Note that these specifications correspond to a difference-in-differences model. ${ }^{12}$

\footnotetext{
${ }^{12}$ It is worth discussing why we do not include in our control group all women aged 58-70. Women in this age group are most likely to be post-menopausal and do not suffer from negative menopausal symptoms anymore. Among these, some are prescribed HRT with the intension of preventing osteoporosis and heart disease. When the WHIS findings were announced, HRT use declined in this group as well. Since these women use HRT for preventive purposes only and do not suffer negative health symptoms after discontinuing it (i.e., HRT use should not impact labor market outcomes), we can still use them to predict the time path of labor market outcomes among women aged 40-55. However, the fact that some women who used HRT discontinued it after the WHIS indicates that including all women aged 58-70 would provide a weaker instrument: the first stage would be weaker. In Section 6, we show that estimates from fixed effects and reduced form models yield qualitatively similar results when using all women aged 58-70 as the control group but we indeed have a much weaker first stage.
} 
In order for the FE IV method to yield consistent estimates of the parameter of interest, three conditions must be satisfied. First, the instrument must be a strong determinant of HRT use (the relevance condition). Figure 1 shows a sizeable decline in HRT use following the release of the WHIS findings, indicating the strong correlation between the timing of the "WHIS intervention" and HRT use. More formally, the relevance condition can be tested using the results of the first stage equation. As a rule-ofthumb, if the first-stage F-statistic testing the significance of the instrument is greater than 10 , then the instrument is considered strong.

A second assumption needed for the FE IV results to be consistent is the instrument excludability. Intuitively, the excludability condition states that the instrument affects labor market outcomes only through its impact on HRT use. In our framework, this means that the control group (women aged 58-70) correctly predicts the time path of the labor market outcomes of the treatment group (women aged 40 to 55) in the absence of the treatment (the release of the WHIS findings). While this is basically an untestable assumption, we suggest its plausibility in two ways. First, we show that the evolution of labor market outcomes between treated and control women follow the same trend before the release of the WHIS findings, lending confidence to the assumption that they would have followed similar trends in the absence of the "WHIS intervention." Second, following Bertrand et al. (2004), we conduct placebo tests and show that there are no significant differences in the labor market outcomes of treatment and control groups during the periods when there was no intervention.

The final assumption needed for the FE IV to yield consistent estimates is monotonicity. This assumption states that while the instrument may not impact all individuals, those who are impacted by it are all impacted in the same way. In particular, it rules out a scenario where the WHIS study findings lead some middle-aged women to increase their HRT use.

Our FE IV strategy identifies the local average treatment effect (LATE) for women who stop using HRT only because of the WHIS findings, but would use it otherwise. This population of "compliers" is likely not a random draw from the population and thus the effect of HRT use may not reflect the average treatment effect. That said, compliers are plausibly more representative of women experiencing menopausal symptoms 
that interfere with or prevent regular activities and thus our LATE has direct pertinence for public policy. We present our results and discuss instrument validity in Section 6.

\section{Estimation Results}

\subsection{Main Results}

Table 2 presents the main results. Fixed effects estimates of $\delta_{1}$ from Equation 1 (reported in Column 1, Row 1) indicate that HRT use increases employment of middle-aged women by 1.9 percentage points or 2.44 percent. ${ }^{13}$ This estimate, which is statistically significant at the 6 percent level, represents the average treatment effect if the strict exogeneity assumption is satisfied.

As discussed previously, FE estimates of HRT use may be biased if there are unobserved timevarying determinants of employment that are also correlated with individual HRT use. The remainder of Table 2 thus presents results from our fixed effects instrumental variable strategy that would alleviate such a bias. The first-stage estimate in Row 2 of Column 2 shows that women aged 40-55 decreased their HRT use on average by 5.3 percentage points after the release of the WHIS findings. This is a substantial reduction when compared to HRT use among this group of women before the announcement of the WHIS findings (14.14 percent). The F-statistic associated with the instrument is 41.09 , well above the rule-of-thumb value of 10 used to assess the strength of the instrument.

In Column 3, we turn to the reduced form relationship between the instrument and the outcome variable. Our results indicate that employment of women aged 40-55 declined by a statistically significant 1.7 percentage points after the WHIS intervention as compared to the change in employment of women in the control group (i.e., those aged 58-70 and do not use HRT). ${ }^{14}$

\footnotetext{
${ }^{13}$ The mean employment rate of women aged 40-55 during the pre-WHIS period is 77.75 percent. Hence, the FE estimate of the impact of HRT use translates to an increase of 2.41 percent $(100 / 77.75 * 1.9=2.44)$. The FE model indicates an increase of 2 percentage points (s.e. 0.007) when all women aged 58-70 is used as the control group.

${ }^{14}$ The first-stage and reduced-form results when using all women aged 58-70 as the control group are -1.4 percentage points (s.e. 0.010) and -1.2 percentage points (s.e. 0.007), respectively. Note that the reduced form estimates are statistically indistinguishable from each other but the first-stage results are not. In particular, in this case the F-statistic testing the significance of the instrument is significantly below 10 .
} 
The last Column of Table 2 combines the first-stage estimates with the reduced-form results to present the local average treatment effect of HRT use on employment. The point estimate suggests that HRT use increases employment among the sample of compliers by 32.6 percentage points. In our context, compliers consist of women who stop using HRT because of the WHIS findings and would continue to use HRT prescriptions otherwise. While it is not possible to identify individual compliers, it is possible to calculate their share among the analysis sample. In particular, when the treatment variable and the instrument are both binary, the share of the compliant subpopulation is given by the first stage coefficient of the instrument. This means compliers comprise 5.3 percent of women aged 40-55. Combined with counts of women aged 40-55 from Census data for 2001-2003 $(33,632,732)$, this implies a national complier population of $1,782,535$.

Two points are worth discussing. First, it is instructive to compare our FE IV estimate of the impact of HRT use on labor market outcomes to the labor market effects of other pharmaceuticals found in other studies. Such a comparison is complicated by the fact that the handful of studies on this topic differs greatly in the way they measure health, the outcome they study, their estimation strategy and the population of interest (Currie and Madrian, 1999). Most directly related to our study are Thirumurthy et al. (2008) and Garthwaite (2012). Thirumurthy et al. (2008) examine the impact of ARV treatment for HIV on the probability of labor force participation in western Kenya and find that ARV treatment is associated with a 20 percent increase in the labor force participation of AIDS patients within six months of treatment initiation. Garthwaite (2012) studies the effect of Vioxx, a commonly prescribed Cox-2 inhibitor, on the labor supply of elderly Americans and finds that the use of Vioxx increases the employment rate of elderly individuals with joint conditions by 38.5 percentage points. Our finding on the economic benefits of HRT use among middle-aged women is consistent with these studies.

Second, it should be kept in mind that we are able to measure the short-term impact of HRT use on the employment of complier women and this effect can be very different from the medium and long-term effects. As discussed before and detailed in Section 6.3, the most plausible channel through which HRT affects employment is menopausal symptoms. It is possible that women who stop using HRT after the WHIS 
findings have difficulty in managing the resurgence of negative menopausal symptoms but find alternative ways to cope with them over the longer term. Nonetheless, our results on the short-term effects of HRT use are still important for informing policy debates.

\subsection{Instrument Validity}

The validity of our FE IV estimate rests on three key assumptions described in Section 5. The point estimates in Column 2 of Table 2, along with the F-statistic associated with the instrument, indicates that our instrument satisfies the relevance condition.

While the excludability assumption cannot be tested formally, in this section we bring evidence on its plausibility in two ways. First, we show that pre-treatment trends in employment are similar among the treatment and control groups, lending support to the claim that the control group is appropriate in predicting the time path of employment among the treatment group in the absence of the WHIS intervention. Figure 3 plots the evolution of employment rates among our treatment and control groups using data from MEPS for the period 1998-2004. The figure shows that pre-WHIS trends in employment are very similar between women aged 40-55 and women aged 58-70 who do not use HRT. However, the trends diverge after the WHIS announcement: the employment rate among the control group increases while employment rate among the treated women shows a decline.

In order to test the equality of pre-treatment trends in employment more formally, we estimate the following equation using the annual household component of MEPS for 1998-2001:

$\mathrm{y}_{\mathrm{it}}=\mathrm{a}_{\mathrm{i}}+\sum_{\mathrm{t}=2}^{\mathrm{T}} \mathrm{b}_{\mathrm{t}}$ year $_{\mathrm{t}}+\mathrm{c}$ Women $4055_{\mathrm{it}}+\mathrm{dX} \mathrm{Xt}_{\mathrm{it}}+\sum_{\mathrm{t}=2}^{\mathrm{T}} \mathrm{g}_{\mathrm{t}}$ year $_{\mathrm{t}} *$ Women $055_{\mathrm{it}}+\omega_{\mathrm{it}}$

The test of equality of pre-trends in employment between women aged 40-55 and women aged 58-70 who do not take HRT is a test that $g_{t}$ are jointly statistically indistinguishable from zero. Our regression results confirm the visual evidence in Figure 3: we cannot reject that $g_{t}$ are jointly equal to 0 with a p-value of 0.38 .

In order to shed more light on the plausibility of the exclusion restriction, we also estimate placebo regressions in the spirit of Bertrand et al. (2004). In particular, we use data from MEPS for the pre-WHIS 
period and assign "fake" intervention years for 1999 and 2000. We then estimate our reduced-form model using these data and the fake intervention indicator. The results, presented in Table 3 , show that these fake intervention years do not have any differential impact on the employment of women in the treatment group relative to those in the control group. The point estimates are both positive (i.e., wrong signed) and statistically insignificant despite the much larger sample size.

The final assumption required for our FE IV results to yield consistent estimates of HRT use on employment is monotonicity. In our context, monotonicity implies that the release of the WHIS findings may not have impacted the HRT use of all women, but all impacted women were less likely to use HRT as a result of the WHIS findings. We see no reason to be concerned about the violation of this assumption. Taken together, the evidence in this section suggests that our instrument satisfies the validity conditions.

\subsection{The Health Channel}

The previous sections show a robust positive effect of HRT use on the employment of middle-aged women. However, the precise mechanism leading to this impact is not clear. Since HRT prescriptions were mainly used for the alleviation of negative menopausal symptoms, the most plausible channel through which HRT use impacts employment is female health. Unfortunately, it is not possible to explore this mechanism using data from MEPS due to two important limitations. The first limitation is the wording of the question assessing general health. The question reads: "I'd like to talk about (PERSON)'s health. In general, compared to other people of (PERSON)'s age, would you say that (PERSON)'s health is excellent, very good, good, fair, or poor?" Consider now the case of a person who reports having good health before the WHIS. This person may feel worse off after the WHIS compared to the period before, but if she believes that people in her age group experienced similar health declines, she might simply (as the question instructs her to do) incorporate the worsening of other people's health in her reference point and still report that she feels in good health. This indicates that we may not be able to detect meaningful changes in health even if there are such changes. Second, MEPS asks questions on other health related questions only in two rounds and the wording of the questionnaire changes between rounds, making them not suitable for our purposes. 
Given the limitations of MEPS, in this section, we refer to prior medical literature examining the association between HRT use and health. Since our LATE results apply to the group of compliers (i.e. those who stopped using HRT as a result of the WHIS but would have kept using it otherwise), particularly relevant for our paper is the study by Cumming et al. (2011). The study, conducted in the UK, surveyed 1100 women (776 of whom were aged 40-60) who stopped using HRT after the WHIS to examine the impact of HRT use on recurrence of menopausal symptoms. The survey revealed that among women who had previously taken HRT for menopausal symptoms, 89.1 percent experienced a return of symptoms and 74 percent indicated that their symptoms were worse. Most importantly for our study, among women who reported a resurgence of menopausal symptoms, 37.5 percent said that these symptoms affected their ability to work, 45.1 percent had problems with decision making, 53.6 percent admitted that their relationships were negatively affected and 29.2 percent said that symptoms affected their social relationships. These findings, combined with previous economic literature linking biological factors to labor market outcomes (e.g., Ichino and Moretti, 2009) suggest that health is indeed a plausible mechanism behind our findings.

\section{Conclusions}

In this paper, we examine the impact of HRT use on the short-term labor market outcomes of middleaged women. We implement a fixed effects instrumental variables strategy that exploits the exogenous variation in HRT use arising from the release of the WHIS findings. Using data from MEPS for the period 2001-2003, we find that HRT use has an economically significant impact on the employment of women aged 40-55. Data limitations do not allow us to directly investigate the role of health in facilitating the beneficial impacts of HRT use on labor market outcomes. However, previous findings from the medical literature provide suggestive evidence that HRT use impacts employment by alleviating negative menopausal symptoms.

Our results represent a local average treatment effect that applies to the subsample of middle-aged women who stop using HRT because of the WHIS findings, but would continue to use it otherwise. While 
compliers unlikely to be representative of the general population of middle-aged women, they are plausibly more representative of women experiencing menopausal symptoms that interfere with or prevent regular activities. This means our results have direct pertinence for public policy.

Given the shrinking cohort sizes and the policy debates on how to keep older workers in the labor market as long as possible, uncovering the role of medical treatments in achieving this goal is a major topic in the research agenda. Our results contribute to this debate by providing an important piece of information that should be taken into account in the cost-benefit analyses of HRT use. 


\section{References}

Acemoglu, D., Autor, D., \& Lyle, D. (2004) Women, war and wages: The effect of female labor supply on the wage structure at mid-century. Journal of Political Economy, 112 (31), 497-551.

Albanesi, S. \& Olivetti, C. (2009). Gender role and medical progress. National Bureau of Economic Research, working paper 14873. Retrieved from http://www.nber.org/papers/w14873.

Angrist, J.D., \& Pische, J.S. (2008). Mostly Harmless Econometrics. Princeton: Princeton University Press.

Angrist, J. D., Imbens, G. (1994). Identification and Estimation of Local Avrage Treatment Effects. Journal of the American Statistical Association, 91 (434). 444-455.

Autor, D. H., Katz, L. F., \& Kearney, M. S. (2008). Trends in U.S. wage inequality: re-assessing the revisionists. Review of Economics and Statistics, 90 (2). 300-323.

Avis, N. E., Crawford S. L. and Sonja McKinlay, "Psychosocial, Behavioral, and Health Factors Related to Menopause Symptomatology" (1997), Women's Health Research on Gender, Behavior, and Policy, 3(2)

Bailey, M.J. (2006). More power to the pill: the impact of contraceptive freedom on women's life cycle labor supply. The Quarterly Journal of Economics, 121, (1). 289-320.

Barnabei et al, (2005). Menopausal Symptoms and Treatment Related Effects of Estrogen and Progestin in the Women's Health Initiative.Obstetrics and Gynecology 105 (5),1063-1073

Barrett, L., Cullis, W. Fairfield, L. and Nicholson, R. ,(1933) "Investigations of the menopause in 1000 women", Lancet 1:106-108

Berecki-Giself, Janneke, Nelufa Begum, Annette J. Dobson. ( 2009). Symptoms reported by women in midlife: menopause transition or aging? Menopause: The Journal of the North American Menopause Society, $16(5) .1021-1029$

Berndt, Ernst, Stan Finkelstein, Paul Greenberg, Robert Howland, Alison Keith, A. John Rush, James Russell, and Martin Keller.(1998) "Workplace performance effects from chronic depression and its treatment,"Journal of Health Economics, 17, 511-535.

Bertrand, M., Duflo, E., \& Mullainathan. S. (2004). How much should we trust difference-in-differences estimates. The Quarterly Journal of Economics, 119 (1). 249-275.

Black, S. E., \& Brainerd, E. (2004). Importing equality: the impact of globalization on gender discrimination. Industrial and Labor Relations Review, 57 (4). 540-559.

Black, S. E., \& Chinhui, J. (2000). The rise of female professionals: women's response to rising skill Demand. American Economic Review, 90 (2). 450-455.

Black, S. E., \& Strahan, P. E. (2001). The division of spoils: rent-sharing and discrimination in a regulated industry. American Economic Review, 91 (4). 814-831.

Bradley, C.J., D. Neumrk, Heather L. Bednarek, Maryjean Schenk,(2005). Short-term effects of breast cancer on labor market attachments: results from a longitudinal study. Journal of Health Economics, 24, 137-160. 
Broekmans, F. J., Knauff, E.A. H., Te Velde, E. R., Macklon, N. S. \& Fauser, B. C. (2007). Female reproductive ageing: current knowledge and future trends. Trends in Endocrinology and Metabolism, 18 (2). $58-65$.

Cameron, C. A. \& Trivedi, P. (2005). Microeconometrics: Methods and Applications. Cambridge: Cambridge University Press.

Cardozo, L., Backmann, G., McClish, D., Fonda, D., \& Birgerson, L. (1998). Meta-analysis of Estrogen therapy in the management of urogenital atrophy in postmenopausal women: second report of the hormones and Urogenital Therapy Committee. Obstetrics \& Gynecology, 92 (4). $722-727$.

Center for Medicaid and Medicare Services, "National Health Expenditure Projections 2007-2017," available online at: http://www.nipcweb.com/NHE Projections.pdf

Cumming, Grant P.,Currie, Heather D., Panay, Nick, Moncur, Rik, Lee, Amanda J.(2011). Stopping hormone replacement therapy: were women ill advised? Menopause International,Vol. 17 Issue 3, p82

Currie, J. \& Madrian, B. (1999). Health, Health Insurance and the Labor Market. In Orley C. Ashenfelter \& David Card (Eds.), Handbook of Labor Economics, Volume 3c (3309-3416). Amsterdam, The Netherlands: Elsevier.

Duggan, Mark and Craig Garthwaite. (2012). Empirical Evidence on the Value of Pharmaceuticals. The Oxford Handbook of the Economics of the Biopharmaceutical Industry, 463-492. Oxford, UK: Oxford University Press.

Fentiman, I. S., D. Allen, M. Wheeler and J. Rymer, (2006) The influence of premenopausal hormones on severity of climacteric symptoms and use of HRT. Climateric 9 (2):135-145

Garthwaite, C., (2012). The Economic Benefits of Pharmaceutical Innovations: The Case of Cox-2 Inhibitors. American Economic Journal: Applied Economics. 4(3): 116-137.

Gardener, D.G. \& Shoback, D. (2007). Greenspan's Basic Endocrinology ( $8^{\text {th }}$ ed.). Blackick, OH: McGrawHill Medical Publishing Division.

Goldin, C. (1990). Understanding the Gender Gap: An Economic History of American Women. New York, NY: Oxford University Press.

Goldin, C. (2006). The 'Quiet Revolution' that transformed women's employment, education and family. The American Economic Review, Papers and Proceedings (Ely Lecture), 1-21

Goldin, C. \& Katz, L. (2002). The Power of the Pill: Oral Contraceptives and Women's Career and Marriage Decisions. Journal of Political Economy, 110 (4). 730-770.

Greendale GA, Reboussm BA, Hogan P, Barnabei VM, Shumaker S, Johnson S, Barrett-Connor E (1998). Symptom relief and side effects ofpostmenopausal hormones: results from the Postmenopausal Estrogen/ProgestinInterventions Trial. Obstet Gynecol 1998; 92: 982-988

Greenwood, J., Ananth, S., \& Mehmet, Y. (2005). Engines of liberalization. Review of Economic Studies, 72 (250). 109-133. 
Hays, J., Ockene, J. K., Brunner, E.L., Kotchen, J. M., Manson, J. E., Patterson, R. E., Argaki, A. K., Shurmaker, S. A., Brzyski, R. G., LaCroix, A. Z., Granek, I. A., \& Valanis, B. G. Effect of estrogen plus progestin on health- related quality of life. The New England Journal of Medicine, 348 (19).

Hemminki, E., Kennedy, D. L., Baum, C. \& McKinlay, S. (1988). Prescribing of non-contraceptive estrogen and progestins in the United States, 1974-1986. American Journal of Public Health 78 (11). 1479-1481.

Ichino, A. and Moretti, E., (2009). Biological Gender Differences, Absenteism and the Earnings Gap. American Economic Journal: Applied Economics, 1:1

Jacobsen, Bjarne K., Ivan Heuch, Gunnar Kvåle.(2003).Age at Natural Menopause and All-Cause Mortality: A 37-Year Follow-up of 19,731 Norwegian Women. American Journal of Epidemiology 157(10). 923-929.

Kennedy, D. et al. , (1985) . Noncontraceptive Estrogen and Progestins: Use Patterns Over Time. Obstetrics and Gynecology 65 (March) 443

Luoto, R., Jaakko Kaprio, Antti Utela (1994). Age at natural Menopause and Sociodemographic Status in Finland. American Journal of Epidemiology 139 (12). 1195-1205.

MacLennan A, Lester S, Moore V. Oral oestrogen replacement therapy versus placebo for hot flushes (Cochrane Review). In The Cochrane Library, Issue 2. Oxford: Update Software, 2001

Mvundura, M., (2007), Menopause Transition and Labor Maket Outcomes, PhD Thesis, Department of Economics, Georgia State University

North American Menopause Society, (2000), A Decision Tree for the use of Estrogen Replacement Therapy in Postmenopausal Women: Consensus Opinion of the North American Menopause Society. Menopause: The Journal of the North American Menopause Society, 7

Ockene, J. K. et al, (2005) Symptoms Experience After Discontinuing Use of Estrogen Plus Progestin. Journal of the American Medical Association, Vol 294(2)

Rokoff, J. and M.A. Hermann, (2010), Does Menstruation Explain Gender Gaps in Absenteism? NBER Working Paper \# 16523

Skinner, J. and D. Staiger, Technological Diffusion of Hybrind Corn to Beta Blockers. in E. Berndt and C. M. Hulten (eds.) Hard-to-Measure Goods and Services: Essays in Honor of Zvi Griliches. University of Chicago Press and NBER

Sturdee, D. W. and N. Panay, (2010). Recommendations for the management of postmenopausal vaginal atrophy. Climateric, 13(6): 509-522

The Women's Health Initiative Study Group, (1998), Design of the Women's Health Initiative Clinical Trial and Observational Study. Controlled Clinical Trials, 19: 61-109

Thirumurthy H, Goldstein M, Graff Zivin J. The Economic Impact of AIDS treatment: labor supply in Western Kenya. Journal of Human Resources 2008; 43: 511-552

Watkins, E.S., (1998), On the Pill: A Social History of Oral Contraceptives, 1950-1970 .Baltimore: The Johns Hopkins University Press 
Watkins, E. S., (2007a), The Estrogen Elixir, Baltimore: The John Hopkins University Press

Watkins, E. S., (2007b). The Medicalisation of Male Menopause in America. Social History of Medicine (20) 2: $369-388$

Watkins, E.S., (2008). Medicine, Masculinity, and the Disappearance of Male Menopause in the 1950s. Social History of Medicine (21)2, 329-344

Weinberg, Bruce A., (2000). Computer use and the demand for female workers. Industrial and Labor Relations Review 53, 290-308

Wysowski,D. K., Linda Golden, and Laurie Burke, (1995) .Use of Menopausal Estrogen and Medroxyprogesterone in the United States, 1982-1992. Obstetrics and Gynecology (85) (1), 6-10

Writing Group for the Women Health Initiative Investigators (2002).Risks and Benefits of Estrogen plus Progestin in Healthy Postmenopausal Women. Journal of The American Medical Association, 288(3):321-333

Wooldridge, J., (2010), Econometric Analysis of Cross Section and Panel Data, Cambridge: The MIT Press. 


\section{FIGURES}

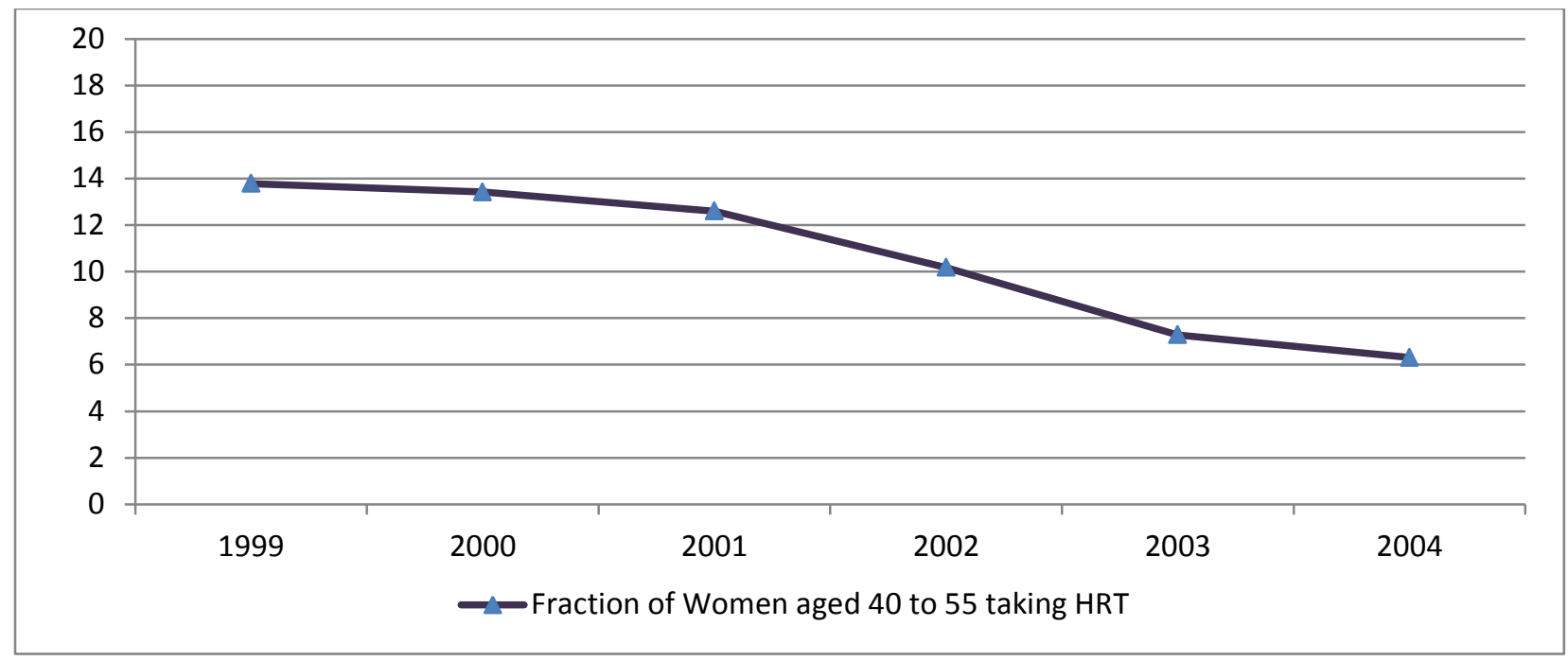

Figure 1: HRT use among women aged 40 to 55, MEPS 1999-2004

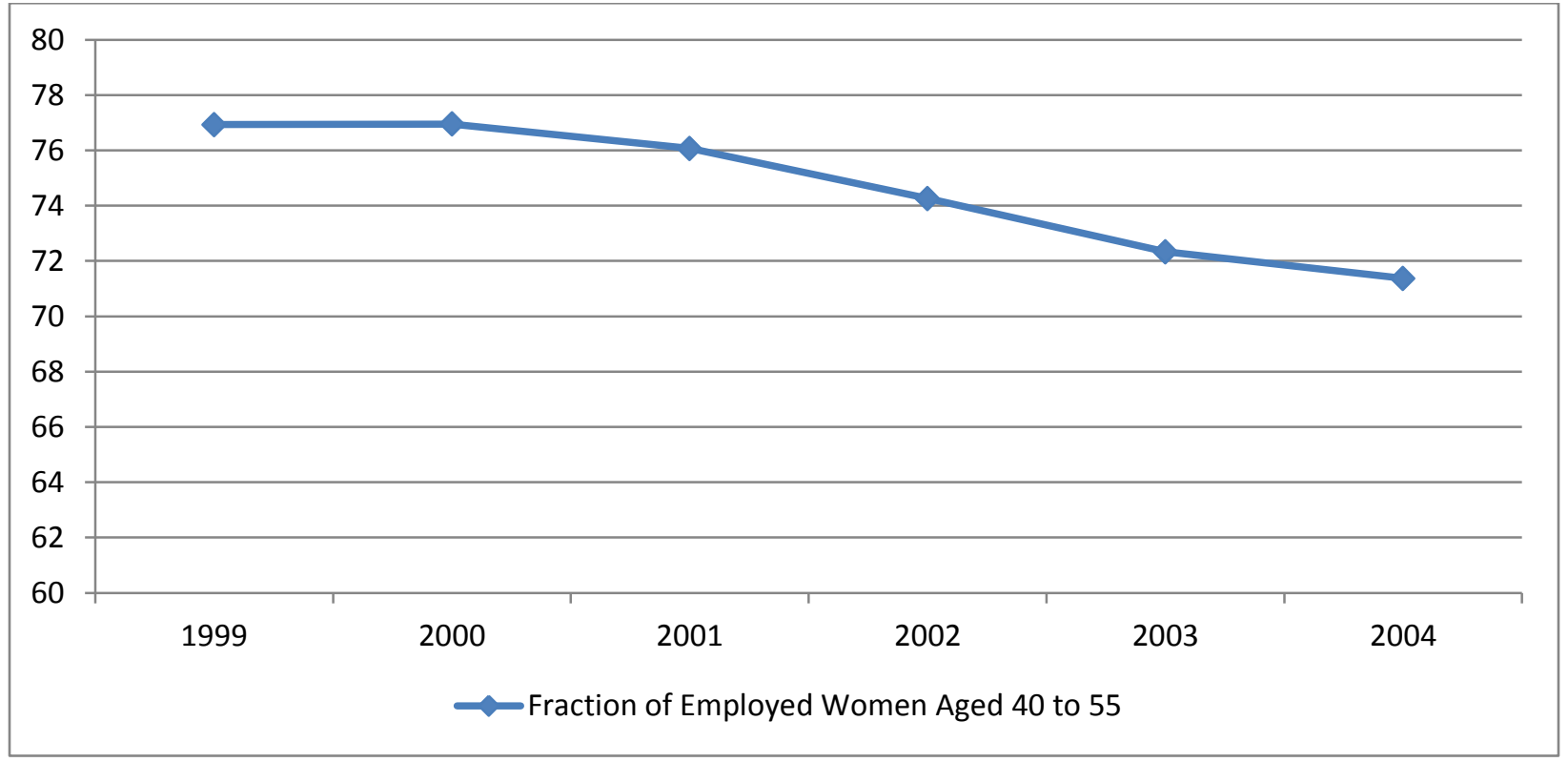

Figure 2: Employment rate of women aged 40 to 55, MEPS 1999-2004

Notes: Data are from MEPS for 1999-2004. A woman is classified as using HRT if at any time during the round she reports having purchased HRT products at least once. She is counted as employed in round $t$ in year $t$ if she reports being employed at the interview date or during the references period for round $t$ reference or if she has a job to return to at the interview date. All statistics are calculated using MEPS longitudinal weights. 


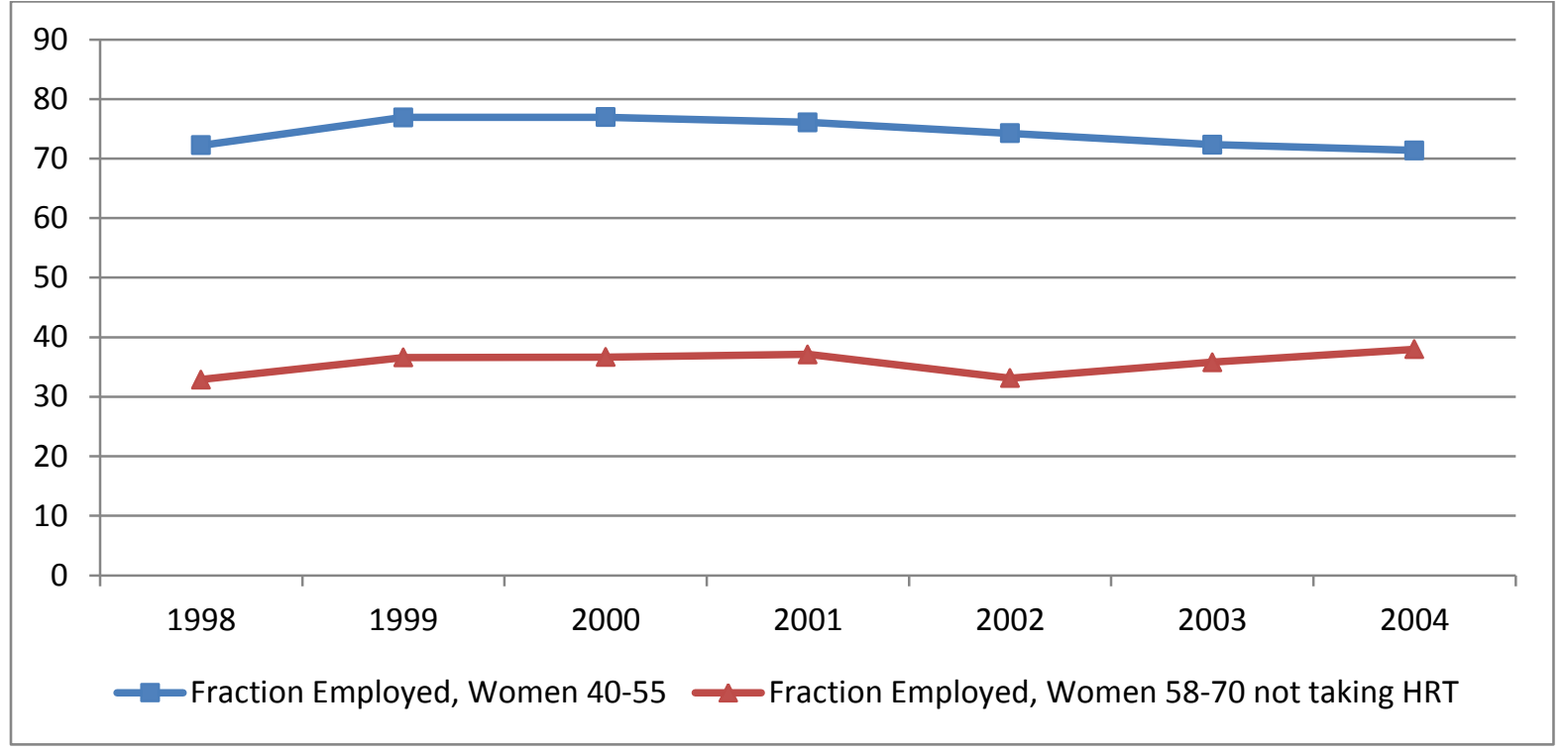

Figure 3: Evolution of employment rates among treatment and control groups, MEPS 1998-2004

Notes: Data are from MEPS for 1999-2004. A woman is classified as employed in round $t$ in year $t$ if she reports being employed at the interview date or during the references period for round $t$ reference or if she has a job to return to at the interview date. All statistics are calculated using MEPS longitudinal weights. 
TABLES

Table 1: Summary Statistics

\begin{tabular}{lc}
\hline \hline Fraction employed & 69.48 \\
Fraction Married & 64.64 \\
Fraction with High School Degree or Equivalent & 48.29 \\
Fraction with a college degree & 15.78 \\
Fraction Taking HRT & 9.14 \\
N & 21,731
\end{tabular}

Notes: Summary statistics. Sample includes Panels 6 and 7 from MEPS corresponding to years 2001-2003. All statistics are calculated using MEPS longitudinal weights.

Table 2: FE and FE-IV Estimation of the Effects of HRT Use on Employment

\begin{tabular}{lcccc}
\hline \hline & $\begin{array}{c}\text { Fixed Effects } \\
(1)\end{array}$ & $\begin{array}{c}\text { First-Stage } \\
(2)\end{array}$ & $\begin{array}{c}\text { Reduced Form } \\
(3)\end{array}$ & $\begin{array}{c}\text { LATE } \\
(4)\end{array}$ \\
\hline $\mathrm{HRT}_{\mathrm{it}}$ & $.019^{*}$ & & & $.326^{* *}$ \\
& $(.010)$ & & $(.148)$ \\
Post $_{\mathrm{t}}{ }^{*}{\text { Women } 4055_{\mathrm{it}}}$ & & $-.053^{* *}$ & $-.017^{* *}$ & \\
$\mathrm{~N}$ & & $(.008)$ & $(.007)$ & \\
\hline
\end{tabular}

Notes: Column 1 presents the effect of HRT use on employment from a fixed effects model. Columns 2-4 provides results from our fixed effects instrumental variables strategy, with Column 3 reporting first stage estimates, Column 4 the reduced-form estimates and Column 5 the local average treatment effect, respectively. All specifications include a cubic in age, a panel specific linear trend, individual and year fixed effects. Robust standard errors clustered at the individual level are shown in parentheses. All estimates use MEPS longitudinal weights. $* \mathrm{p}<0.10, * * \mathrm{p}<0.05, * * * \mathrm{p}<0.01$.

\section{Table 3: Placebo Regressions}

\begin{tabular}{lcc}
\hline & Intervention: 1999 & Intervention: 2000 \\
& $(1)$ & $(2)$ \\
\hline Post $_{\mathrm{t}}{ }^{*}$ Women4055 & .013 & .025 \\
$\mathrm{it}$ & $(.016)$ & $(.015)$ \\
$\mathrm{N}$ & 49,730 & 49,730 \\
\hline
\end{tabular}

Notes: Regressions use data from the household component of MEPS for the pre-WHIS period. Each column presents the effect of a fake-intervention on the employment of women aged 40-55 (as compared to those aged 58-70 who do not use HRT) from a difference-in-differences model. All specifications include a cubic in age, a panel specific linear trend, individual and year fixed effects. Robust standard errors clustered at the individual level are shown in parentheses. All estimates use MEPS longitudinal weights.

$* \mathrm{p}<0.10, * * \mathrm{p}<0.05, * * * \mathrm{p}<0.01$. 